Understanding the future

\section{Transitions and paradigms}

\section{Leonard Duhl}

\section{"Poverty is the inability to command events that affect our lives."}

A t this important time of crisis, I am reminded of the work of three of my good friends: Jonas Salk, Ernest Callenbach, Tarzie Vittachi. Each has contributed something very important in trying to understand the future.

Jonas Salk, involved with bacteriology, chose as a metaphor the $\mathrm{S}$ shaped curve. In this curve, he states that when resources are infinite the growth of bacteria is rapid. There is competition, a self concern, and a preoccupation with growth. Later, when the resources become diminished, there is a need to replace competition with collaboration, the birth rate slows down, and a completely new value system emerges. The period between the two curves he calls a transition period. This is a transition between what he calls epoch $\mathrm{A}$ and epoch B. He believes that we are now in the midst of that transition. Transitions are uncomfortable and often chaotic. Time is required, and as the Bible relates going from Egypt to the Promised Land took 40 years. One might say it took that long for the old people and the ideas to be replaced by new ones.

Ernest Callenbach has written a book called Ecotopia. This book, although a novel, tries to create an area where new values are supreme. The values that he considers important are sustainability of the environment, a happy life, living with the natural world, and living collaboratively. This is more like Jonas Salk's epoch B. We are obviously not there, it is important to have a vision of the world we would like to have. To understand Callenbach's views one has to live in a world of systems and ecology. One must also understand that the systems are constantly changing in their relationships and we must constantly adapt to these changes. It also implies a set of values that puts psychological, social, biological, and other humanistic needs above economic ones. Bean counters are less loved in this world, than those involved in process, human relations, networking, and community.

Tarzie Vittachi, the former deputy director of Unicef always reminded us, that "the news behind the news" was more important than the news itself. To me this forces a look not at the symptoms, but the underlying complex processes behind the event. Much of our current response in health and otherwise is to deal with the symptoms and to ignore the underlying complex processes that appear chaotic. Most policy responds in this manner: medicines to cure disease, military action to respond to social unrest, and arresting the local drug provider. In each of these cases looking at the underlying issues is fraught with danger, as it raises questions about our values. It forces us to question authority, common knowledge, and the accepted way of doing things.

Those of us who have been involved in Healthy Cities are part of the experimental group looking to a new paradigm. But, we are not alone. People concerned with the environment, education, transportation, housing, and even the law are becoming increasingly aware, and using these new paradigms. Although the thoughts about the ecological and systems models of health and cities have been with us since the 1960s, it is only now that the Institute of Medicine in Washington has called for it ecological look at medical care and health.

Health is important in leading the way to the future. As we struggle with finding answers to the meaning of health, such as in the Ottawa Charter, and others, we are contributing to understanding how to look differently at the world.

What I want to do is to place Healthy Municipalities (Cities), in the context of the changing American world. My basic position is that we are in the midst of a major change in society, with health leading the way. The changes are of course world wide; geographical to a virtual world, increased participation of the civic sector, and the fact that issues cannot be dealt with in isolation. The Healthy Cities point of view is the anticipation of major changes, in many other fields. Pattern changes are obvious all over the Western hemisphere.

The Americas are rapidly changing their process of governance from an authoritarian hierarchical model, to an increasingly democratic, participatory one. With large migrations of populations, decentralisation from national power, and collaboration between countries, critical to each, yet part of a larger issue, new ways of funding are gradually being looked at, as is taxation, the building of community power, and maintaining the individuality of these diverse populations. The increased diversity of population, the vast movement to urbanisation, and the communications revolution are refining problems, as a set of complex interrelated ever changing systems.

In planning, the processes involved are as important as the data, the question more important than the answer. Rather than defining health as medical care alone, Healthy Cities has lead the way to seeing that health promotion, involving all sectors of our communities, is central to the processes of solution.

The symptoms of both the failure of old solution and the emerging change are widespread-poverty, inadequate housing, drugs, corruption, environmental pollution, emerging and new patterns of illness, and more. Hitherto, we have used the provisions of services as the solution. Now, in contrast, we are seeing those persons concerned central to its solution. Our focus on development has been primarily economic. It is clear both in Healthy Cities communities, and in the UNDP reports that the quality of life is more critical than increasing the gross national product. City report cards are beginning to serve as guides to the processes of change.

That, Healthy Cities focus, is on the whole community-because it emphasises active participation of all sectors, and focuses upon achieving equity, and building personal and social competence to deal with issues has been its main attraction to Latin Americans. New programmes outside of Healthy Cities have used similar principles. Environmental concerns, central to health are leading the change towards achieving sustainable communities. New programmes for local food production, new education and schooling, transportation models, land ownership, housing and social services are the areas where this is happening. The solutions are not governmental alone. It will involve the business section, communities, separate interests, the faith community and more, to make the process work.

These processes are not all working well, however, those that are, are leading the changes in health. Rather that the medical profession and its immediate allies being the ones responsible 
for health, it is gradually becomes that of the people itself. "Poverty is the inability to command events that affect our lives." Thus learning those skills is central to solutions.

Avian flu
Healthy Municipalities had led the way, to new health.

$J$ Epidemiol Community Health 2004;58:806-807.

doi: 10.1136/jech.2004.021139

\section{Avian influenza: a human pandemic threat?}

\section{Giovanni Rezza}

\section{Another influenza pandemic in humans is inevitable}

n January 2004, the most serious outbreak of avian influenza in terms of the number of human deaths (22 deaths out of a total of 33 cases in Vietnam and Thailand) began. This outbreak was caused by the viral subtype $\mathrm{H} 5 \mathrm{Nl}$ ( $\mathrm{H}$ (haemoagglutinin) and $\mathrm{N}$ (neuraminidase) are viral surface proteins that define specific subtypes) and, to date, constitutes the largest epidemic in commercial poultry, ${ }^{12}$ affecting a number of Asian countries (that is, Cambodia, China, Indonesia, Japan, Lao People's Democratic Republic, and the Republic of Korea, in addition to Thailand and Vietnam), where more than 100 million birds either died or were culled in the first two months of 2004. ${ }^{3}$ The high case fatality rate, together with the potential occurrence of human epidemics, have created great public health concern, given the viruses' high pathogenicity in humans. The question that remains unanswered, and that is the basic cause of such concern, is: "Will this avian virus be able to cause a large scale epidemic among humans after mutation or reassortment?"

To answer this question, we have to consider what we already know. The natural reservoir of avian influenza viruses is wild aquatic birds, which may be infected with "avirulent" or "low pathogenic" strains of the virus and present with only mild symptoms or no symptoms at all. Low pathogenic viruses can infect domestic poultry and other intermediate hosts and develop into highly pathogenic viruses (usually the $\mathrm{H} 5 \mathrm{Nl}$ subtype), which cause a highly lethal disease, once defined as "fowl plague" (fowl plague was first identified in 1878 by an Italian scientist, Edoardo Perroncito, who described an outbreak of a contagious disease affecting domestic birds in farms near Turin, Italy). ${ }^{5}$ Influenza viruses are secreted from the intestinal tract into the faeces of infected birds, and the modes of transmission may be either direct or indirect. Transmission from animals to humans is apparently rare: avian influenza viruses do not replicate efficiently in humans, and receptor specificity is a determinant of a certain host range restriction. ${ }^{6}$

The first recorded instance of direct transmission to a human host occurred in Hong Kong in 1997 and involved different strains of the same subtype implicated in the current outbreaks (H5Nl). Of the 18 persons infected, six died, with the case fatality exceeding $30 \% .{ }^{67}$ The avian influenza subtype, H9N2, crossed the species barrier in 1999, causing mild illness in two children in Hong Kong. ${ }^{8}$ In February 2003, two members of a family, returning to Hong Kong after having travelled to southern China, became ill, and one of them died, again from $\mathrm{H} 5 \mathrm{Nl}$ avian influenza. ${ }^{9}$ In April 2003, another avian influenza viral subtype, H7N7, which had caused an extensive epidemic among poultry, caused the death of a veterinarian and an outbreak of conjunctivitis or mild influenza-like illness among 85 persons who had handled infected chickens, in addition to family members. ${ }^{10}$ In mid-December 2003, H9N2 infection was detected in a child in Hong Kong hospitalised with influenza symptoms, later recovering. ${ }^{11}$ Finally, in early 2004, during a poultry outbreak attributable to another $\mathrm{H} 7$ influenza strain, the H7N3 subtype, in British Columbia, Canada, two laboratory confirmed human cases with conjunctival and upper respiratory symptoms were reported, and at least 10 other poultry workers developed similar symptoms. ${ }^{12}$ This chronology of event indicates that avian to human transmission, although apparently rare, can occur, and that at least four different subtypes are involved.
Correspondence to: Professor L Duhl, School of Public Health, University of California at Berkeley, 410 Warren Hall, Berkeley 94720-7360,

USA; len-duhl@

socrates.berkeley.edu

Regarding human to human transmission of avian influenza strains, little evidence is available. In addition to the family members of poultry workers who acquired H7N7 in the Netherlands, the results of a serosurvey conducted in Hong Kong showed that one of the 54 healthcare workers tested had increased antibody titres, suggesting that transmission of $\mathrm{H} 5 \mathrm{Nl}$ from infected patients may occur, $^{13}$ whereas inter-human transmission was not confirmed in a family cluster investigated in Vietnam during the $2004 \mathrm{H} 5 \mathrm{Nl}$ outbreak. Finally, there was no evidence of human to human transmission of H9N2 in Hong Kong in 1999. ${ }^{14}$

Although this evidence suggests that human to human transmission is inefficient, the potential for viruses to mutate must be considered. Influenza A viruses are known to undergo small or large antigenic changes (that is, drifts and shifts), and major changes can result in worldwide pandemics, such as those of "Asian" flu in 1957 and "Hong Kong" flu in 1968. These changes are often attributable to the reassortment (in pigs or even in coinfected humans) of avian with human influenza strains. In stochastic terms, the higher the frequency of inter-species passage the higher the risk of humans becoming suitable hosts, as the risk of a reassortment event is proportional to the number of hosts coinfected with human and avian strains. ${ }^{15}$

Based on the above information, it is not possible to predict whether or not a large scale epidemic of avian influenza virus among humans is in the making. None the less, we must consider the potential for this to occur. Obviously, the response to this threat of an epidemic must be prompt and efficient. Because of the size of the population of the wild bird reservoir, avian influenza is not an eradicable disease. At present, the most that can be done is to prevent interspecies passage to pigs or humans during fowl epidemics through the mass culling of infected or exposed poultry, which proved to be effective in halting the epidemic in Hong Kong in 1997. ${ }^{16}{ }^{17}$ To prevent the re-emergence of avian viruses, other initiatives can be adopted, although in Hong Kong the re-emergence of $\mathrm{H} 5 \mathrm{Nl}$ was not completely prevented by the elimination of live aquatic birds (for example, ducks and geese) and intermediate hosts (for example, quails) from wet markets (live animal markets), or by the active 
surveillance and use of inactivated vaccines in poultry farms. ${ }^{16}$ In fact, the role of these vaccines remains controversial. ${ }^{18}$ The best option for preventing re-emergence, and thus interspecies passage, would definitely be that of eliminating live poultry markets, which provide optimum conditions for the amplification of influenza viruses. However, the elimination of wet markets is not a realistic goal, at least for the near future, given that these markets are an integral part of the food culture of Asian countries, where older generations do not buy frozen or refrigerated products. ${ }^{16} 19$

If the virus were to become capable of efficient human to human transmission, traditional public health measures, such as quarantine and contact tracing and isolation, as well as travel restriction, which were successful in controlling the epidemic of SARS, would not be likely to work, as influenza might have a considerably higher basic reproductive rate, $R_{0}$ (that is, the average number of secondary cases generated by an infected host). ${ }^{20}$ However, some models have predicted an initial adaptation of a new pandemic virus, with limited initial efficiency in terms of human to human transmission. ${ }^{21}$ In such a case, traditional public health measures, triggered by early recognition of the infection (that is, through good surveillance and the availability of rapid and reliable diagnostic tests), along with the use of prophylactic antiviral treatment (neuraminidase inhibitors), as occurred in the Netherlands, ${ }^{22}$ might help to reduce further transmission, allowing more time for a vaccine to be developed. ${ }^{23}$ To this end, stockpiling of sufficient quantities of antiviral drugs should be considered in preparedness plans. Although an effective vaccine could feasibly be developed, large scale production would not be easy, and the decision to perform mass vaccination, which must obviously be timely, could be affected by past experience, such as the costly 1976 swine flu campaign in the United States, where the epidemic turned out to be a false alarm. ${ }^{24}$

Although another influenza pandemic in humans is inevitable, we cannot predict when it will occur. In the meantime, we must do everything in our power to avert this threat, which means improving our responsiveness to a pandemic alert through implementation of all possible preventive strategies.

\section{ACKNOWLEDGEMENTS}

I would like to thank Andrej Trampuz, Karl Ekdahl, and the two other anonymous referees for their comments and suggestions, and Mark Kanieff for linguistic revision of the manuscript.

$J$ Epidemiol Community Health 2004;58:807-808.

doi: 10.1136/jech.2004.022079

Correspondence to: $\operatorname{Dr} G$ Rezza, Epidemiology Unit, Department of Infectious Diseases, Istituto Superiore di Sanità, Rome, Italy; g.rezza@iss.it

\section{REFERENCES}

1 WHO. Avian influenza A (H5N1). Wkly Epidemiol Rec. 2004;79, 65-76 (http:// www.who.int/wer).

2 WHO. Confirmed human cases of influenza $A$ (H5N1). http://www.who.int/csr/disease/ avian_influenza/country/cases_table 2004_03_10/en (accessed 10 Mar 2004).

3 Fleck F. Avian flu virus could evolve into dangerous human pathogen, experts fear. Bull WHO 2004;82:236-7.

4 WHO. Avian influenza A (H5N1)- update 31: situation (poultry) in Asia: need for a long-term response, comparison with previous outbreaks. http://www.who.int/crs/don/2003_02_27a/en (accessed 2 Mar 2004).

5 Perroncito E. Epizoozia tifoide nei gallinacei. Torino: Annali Accademia Agricoltura, 1878;21:87-126.

6 Horomoto T, Kawaoka Y. Pandemic threat posed by avian influenza. Clin Microbiol Rev 2001;14:129-49.
7 Yuen KY, Chan PKS, Peiris M, et al. Clinical features and rapid viral diagnosis of human disease associated with avian influenza $\mathrm{A} \mathrm{H} 5 \mathrm{~N} 1$ virus. Lancet 1998;351:467-71.

8 Peiris $M$, Yuen $K Y$, Leung $C W$, et al. Human infection with influenza H9N2. Lancet 1999:354:916-17.

9 WHO. Influenza A ( $\mathrm{H} 5 \mathrm{~N} 1)$ in Hong Kong Special Administrative Region of China-Update 2. http:// www.who.int/crs/don/2003_02_27a/en.

10 Fouchier RA, Schneeberger PM, Rozendaal FW, et al. Avian influenza A virus (H7N7) associated with human conjunctivitis and a fatal case of acute respiratory distress syndrome. Proc Natl Acad Sci 2004;101:1356-61.

11 WHO. Influenza A (H9N2) in Hong Kong Special Administrative Region of China (SAR). http:// www.who.int/crs/don/2003 02 _12 10/en.

12 CDC. Interim report: human infection with avian $\mathrm{H} 7$ influenza viruses, North America. http:// www.cdc.gov/flu/avian/interim-report.htm (accessed 2 Apr 2004).

13 CDC. Update: isolation of avian influenza A (H5N1) viruses from humans - Hong Kong, 1997-1998. MMWR 1998;46:1245-7.

14 Uyeki TM, Chong YH, Katz JM, et al. Lack of evidence for human-to-human transmission of avian influenza $A$ (H9N2) viruses in Hong Kong, China 1999. Emerg Infect Dis 2002;8:154-9.

15 Ferguson NM, Fraser C, Donnelly CA, et al. Public health risk from the avian $\mathrm{H} 5 \mathrm{~N} 1$ influenza epidemic. Science 2004;304:968-9.

16 WHO. Avian influenza $\mathrm{H} 5 \mathrm{~N} 1$ infection in humans: urgent need to eliminate reservoirupdate 5. http://www.who.int/csr/don/ 2004 01_22/en/.

17 Webster RG. Wet markets - a continuing source of severe acute respiratory syndrome and influenza? Lancet 2004;363:234-6.

18 Tollis M, Di Trani L. Recent developments in Asian influenza research: epidemiology and immunoprophylaxis. Vet J 2002; 164:202-15.

19 Anonymous. Avian influenza: the threat looms. Lancet 2004:363:257.

20 Webby RJ, Webster RG. Are we ready for pandemic influenza? Science 2003;302:1519-22.

21 Spicer CC. The mathematical modelling of influenza epidemics. Br Med Bull 1979:35:23-8.

22 Koopman $M$, Wilbrink B, Conyn $M$, et al. Transmission of H7N7 avian influenza $A$ virus to human beings during a large outbreak in commercial poultry farms in the Netherlands. Lancet 2004;363:587-93.

23 Longini IM Jr, Halloran ME, Nizam A, et al. Containing pandemic influenza with antiviral agents. Am J Epidemiol 2004:159:623-33.

24 Garrett L, the American Bicentennial. Swine flu and legionnaires' disease. The coming plague. New York: Penguin Books, 1995:153-91. 